\title{
Clinical manifestations of testicular adrenal rest tumor in males with congenital adrenal hyperplasia
}

\author{
Min Kyung Yu, MD', \\ Mo Kyung Jung, MD', \\ Ki Eun Kim, MD', \\ Ah Reum Kwon, MD', \\ Hyun Wook Chae, MD', \\ Duk Hee Kim, MD², \\ Ho-Seong Kim, MD, PhD'
}

${ }^{1}$ Department of Pediatrics, Severance Children's Hospital, Endocrine

Research Institute, Yonsei University College of Medicine, Seoul,

²Department of Pediatrics, Sohwa

Children's Hospital, Seoul, Korea
Received: 7 July, 2015

Revised: 19 August, 2015

Accepted: 21 September, 2015

Address for correspondence:

Ho Seong Kim, MD, PhD

Department of Pediatrics,

Severance Children's Hospital,

Endocrine Research Institute, Yonsei

University College of Medicine, 50-1

Yonsei-ro, Seodaemun-gu, Seoul

03722, Korea

Tel: +82-2-2228-2050

Fax: +82-2-393-9118

E-mail:kimho@yuhs.ac
Purpose: In male patients with congenital adrenal hyperplasia (CAH), the presence of testicular adrenal rest tumors (TARTs) have been reported, however their prevalence and clinical manifestations are not well known. Untreated TARTs may lead to testicular structural damage and infertility. This study was conducted to investigate the prevalence of TARTs in male patients with $\mathrm{CAH}$, and characterize the manifestations to identify contributing factors to TART.

Methods: Among $102 \mathrm{CAH}$ patients aged 0-30 years, 24 male patients have been regularly followed up in our outpatient clinic at Severance Children's Hospital from January 2000 to December 2014. In order to reveiw the characteristics of TART patients, we calculated the mean levels of hormones during the 5 years before the time of investigation. Five patients underwent follow-up scrotal ultrasonography (US) after adjusting the dosage of glucocorticoids.

Results: TARTs were detected in 8 of the 13 patients (61.5\%). The median age of TARTs diagnosis was 20.2 years with the youngest case being 15.5 years old. The mean serum level of adrenocorticotropic hormone (ACTH) was higher in the TARTs patient group compared to the non-TARTs group $(P<0.05)$. The tumor size decreased in 3 cases, slightly increased in 1 case, and had no change in another case.

Conclusion: The serum ACTH level might be associated with the growth promoting factor for TARTs, but the exact mechanism has not been clearly identified. Screening for TARTs using US is important in male patients with CAH for early-detection and prevention of ongoing complications, such as infertility.

Keywords: Congenital adrenal hyperplasia, Adrenal rest tumor, Adrenocorticotropic hormone

\section{Introduction}

Congenital adrenal hyperplasia (CAH) is a common endocrine disease whose incidence ranges from 1:10,000 to $1: 20,000$ births $^{1)}$, and is passed on in an autosomal recessive pattern $^{2,3)}$. It is caused by a defect in adrenal steroid synthesis, with more than $90 \%$ of cases being caused by 21-hydroxylase deficiency (21-OHD). The 21-OHD induces glucocorticoid and mineralocorticoid deficiency, the lack of which leads to a compensatory increase in adrenocorticotropic hormone (ACTH) secretion. This, in turn, causes adrenal gland hyperplasia and overproduction of the adrenal androgens. The 21-OHD is divided into salt wasting (SW) type and simple virilizing (SV) type, according to the with electrolyte imbalance and depending on the severity of the enzyme defect ${ }^{3}$.

In male CAH patients, one of the most important complications is infertility. Many explanations for the infertility have been proposed; however, testicular adrenal rest tumors (TARTs) are known to be the most important cause of infertility in these patients ${ }^{4-6}$. TARTs were first described in 1940 by Wilkins et al. (quoted from ${ }^{7)}$ ), and many case reports have been published subsequently ${ }^{8}$. The prevalence of TARTs in CAH patients has not been 
clearly established yet. Previous studies have showed that the prevalence varies from $0 \%-94 \%{ }^{6,9-11)}$, depending on patient selection (age and hormonal control) and tumor detection methods (palpation, ultrasonography [US], or magnetic resonance imaging ${ }^{12)}$.

The etiology and contributing factors of the tumors were not determined, however some hypotheses have been suggested. Adrenal tissue remnants in the testis can be observed in normal neonates $(7.5 \%-15 \%)$, with most cases regressing during infancy ${ }^{13-16)}$. However, in patients with $\mathrm{CAH}$, chronically elevated ACTH may block regression of the adrenal tissue remnants and induce hyperplasia, eventually resulting in tumor development ${ }^{17)}$. Although this is one possible hypothesis regarding TART development, the exact etiology has not been fully explained.

TARTs can compress the adjacent testicular tissues, which induces seminal tubule obstruction, resulting in oligospermatogenesis $^{6,9)}$. It is a proven risk factor for infertility, and development of tumor and increase in tumor size may start in child$\operatorname{hood}^{17,18)}$. Therefore, early screening and diagnosis of TARTs, with appropriate treatment, are important for protection against gonadal failure and infertility ${ }^{19)}$.

This study was conducted to determine the prevalence of TARTs in our group of male CAH patients using scrotal US, and to define the factors that contribute to TART development by comparing the laboratory findings and clinical presentations of TART and non-TART patients. Furthermore, we compared the follow-up results of scrotal US among the TARTs patients in order to determine any associations between dose adjustment of hydrocortisone treatment and changes in tumor size.

\section{Materials and methods}

Among 102 patients aged $0-30$ years old diagnosed as CAH, 24 male patients have been regularly followed up in our outpatient endocrine clinic at Severance Children's Hospital from January 2000 to December 2014. In all patients, the diagnosis was based on symptoms and laboratory tests, and in some patients, molecular genetic analysis of 21-OHD was performed. Among the 24 patients, 13 underwent scrotal US.

We retrospectively reviewed the medical records; basic anthropometric measurements (height, weight, and body mass index); and biochemical parameters, such as serum 17-hydroxyprogesterone (17-OHP), ACTH, renin activity, and testosterone. The follow-up interval of the patients in our outpatient clinic was 3 months, and physical examination and laboratory tests were performed at each visit. Pubertal status was estimated according to Tanner staging, and the Prader orchidometer was used for measuring testicular volume $\mathrm{e}^{20)}$. The hormonal levels were estimated at a consistent time before the patients taking the morning medications. The serum hormone levels were estimated on the basis of the serum 17OHP (normal range, $0.59-3.44 \mathrm{ng} / \mathrm{mL}$ ), ACTH (normal range, $7.2-63.3 \mathrm{pg} / \mathrm{mL}$ ), renin activity (normal range $1.31-3.95 \mathrm{ng} /$ $\mathrm{mL} / \mathrm{hr}$ ), and testosterone (normal range, $249-836 \mathrm{ng} / \mathrm{dL}$ in
Tanner stage 5) levels. Serum ACTH levels were measured by electrochemiluminescence immunoassay and the Cobas e411 analyzer using the Roche kit. Serum 17-OHP and renin activities were measured using the enzyme-linked immunosorbent assay kit (DRG instruments GmbH, Marburg, Germany). Serum testosterone levels were measured by the chemiluminescent microparticle immunoassay method on an Architect i2000 analyzer using the Architect/Abbott kit. All patients were treated with hydrocortisone 2-3 times a day. In patients with the SW type, fludrocortisone was added to the treatment regimen. We defined the adequate control of CAH as serum 17-OHP and ACTH levels less than $10 \mathrm{ng} / \mathrm{mL}$ and $70 \mathrm{pg} / \mathrm{mL}$, respectively ${ }^{21)}$.

Scrotal US was chosen for the diagnosis of TARTs in $\mathrm{CAH}$ patients, because it is a cheap, noninvasive, and easily accessible method ${ }^{9,22)}$. All US evaluations were performed in our hospital by radiologists with extensive experience. Highresolution ultrasound (Acuson Sequoia 512, Siemens Medical Solutions USA, Mountain View, CA, USA, or LOGIQ 9, General Electronics Company, Milwaukee, WS, USA) and a 12- to 15$\mathrm{MHz}$ linear probe were used for this evaluation. The diameter of TARTs was assessed in at least two dimensions (transverse and longitudinal) by caliper. The diagnosis was confirmed when the scrotal US demonstrated heterogeneous, hypoechogenic areas surrounding the echogenic testis mediastinum with welldefined margins ${ }^{10,16,23,24)}$. In 2009, Claahsen-van der Grinten et al. ${ }^{12)}$ suggested a staging system for TARTs. We classified the tumors into five different stages according to this staging system. Stage 1 is the presence of adrenal rest cells within the rete testis, not detectable by scrotal US. Stage 2 means the adrenal rests cells might be visible on US. Stage 3 means further growth of the adrenal rest cells with compression of the rete testis. Stage 4 means further hypertrophy and hyperplasia of the adrenal rest cells with progressive obstruction of the rete testis with induction of fibrosis and focal lymphocytic infiltrates. Stage 5 means chronic obstruction and irreversible damage of the testicular parenchyma.

In order to compare the characteristics of TART patients with non-TART patients, we calculated the mean levels of the above hormones during the 5 years before the time of investigation. The renin activity was not included since these were not measured in patients with the SV type. Differences of the clinical and biochemical parameters between the two groups that were classified according to the existence of TARTs were assessed by the Mann-Whitney $U$-test. The IBM SPSS Statistics ver. 20.0 (IBM Co., Armonk, NY, USA) was used to analyze each outcome measured. $P$-values of $<0.05$ were considered significant.

\section{Results}

Among the 24 male CAH patients, scrotal US was performed in 13 patients. All of the patients were diagnosed with the classic form of CAH due to 21-OHD. Eight of the 13 patients had the SW type, while 5 had the SV type of CAH. The 13 patients were all in Tanner 5 pubertal stage with a median age of 20.5 years (range, 15.5-29.4 years). The clinical characteristics and 
laboratory results of the patients who had scrotal US are listed in Table 1. Patients with the SW type were all diagnosed as CAH during the neonatal or infancy period. The patients with the SV type were diagnosed between 1 and 15 years of age. None of the patients were suspected as TART clinically before performing the scrotal US, indicating that all patients demonstrated no remarkable findings on physical examination.

TARTs were detected in 8 of the 13 patients (61.5\%). The median age at which TARTs were diagnosed was 20.2 years with the youngest case being 15.5 years old. The prevalence of the SW type (6 of the 8 patients, $75 \%$ ) and SV type (2 of the 5 patients, $40 \%$ ) of TARTs did not differ significantly. Regarding the results of molecular studies performed on 2 patients with TARTs, case 1 was homozygous for p.Ile172Asn mutation while case 2 was homozygous for the c.293-13C>G mutation. We considered serum 17-OHP or ACTH levels above $10 \mathrm{ng} / \mathrm{mL}$ or $70 \mathrm{pg} / \mathrm{mL}$, respectively, as representative of uncontrolled disease. There were 6 (out of $8,75 \%$ ) and 1 (out of 5,20\%) patients with uncontrolled disease in the TARTs and non-TARTs patient groups, respectively.

We tried to compare the overall clinical characteristics and the extent of hormonal controls between the TARTs and nonTARTs patient groups. The result is listed in Table 2. The median dose of hydrocortisone equivalent during the 5 years before conducting the first scrotal US was $21.1 \mathrm{mg} / \mathrm{m}^{2}$ and $22.2 \mathrm{mg} /$ $\mathrm{m}^{2}$ in the TARTs and non-TARTs patient groups, respectively, which were not statistically significant. The mean serum 17 $\mathrm{OHP}, \mathrm{ACTH}$, and testosterone levels during the 5 years before

Table 1. A comparison of the individual clinical characteristics and laboratory results of CAH patients with and without TARTs

\begin{tabular}{|c|c|c|c|c|c|c|c|c|c|c|c|}
\hline \multirow[b]{2}{*}{ Case } & \multirow[b]{2}{*}{ Type of CAH } & \multirow{2}{*}{$\begin{array}{c}\text { Age at } \\
\text { diagnosis of } \\
\text { CAH (yr) }\end{array}$} & \multirow{2}{*}{$\begin{array}{l}\text { TARTs on } \\
\text { scrotal US } \\
(\mathrm{R} / \mathrm{L})\end{array}$} & \multirow{2}{*}{$\begin{array}{c}\text { Age at 1st } \\
\text { scrotal US } \\
(y r)\end{array}$} & \multirow{2}{*}{$\begin{array}{l}\text { Age at } \\
\text { diagnosis of } \\
\text { TARTs (yr) }\end{array}$} & \multirow[b]{2}{*}{$\begin{array}{l}\text { Tanner } \\
\text { stage }\end{array}$} & \multicolumn{4}{|c|}{$\begin{array}{l}\text { Serum hormone levels } \\
\text { (at the time of scrotal US) }\end{array}$} & \multirow[b]{2}{*}{ Genotype Allel1/Allel2 } \\
\hline & & & & & & & $\begin{array}{c}\text { ACTH } \\
(\mathrm{pg} / \mathrm{mL})\end{array}$ & $\begin{array}{l}\text { 17-OHP } \\
(\mathrm{ng} / \mathrm{mL})\end{array}$ & $\begin{array}{c}\text { Renin } \\
\text { activity } \\
\text { (ng/mL/hr) }\end{array}$ & $\begin{array}{l}\text { Testosterone } \\
(\mathrm{ng} / \mathrm{dL})\end{array}$ & \\
\hline \multicolumn{12}{|c|}{ Patients with TARTs } \\
\hline 1 & 21-OHD.SV & 7.2 & $-/+$ & 18.5 & 18.5 & 5 & 328.5 & 74.30 & 5.95 & 386 & p.lle172Asn/p.lle172Asn \\
\hline 2 & 21-OHD, SV & 15.6 & $+/+$ & 21.0 & 21.0 & 5 & 1,344 & 103.9 & 10.12 & 405.9 & c. $293-13 C>G / c .293-13 C>G$ \\
\hline 3 & 21-OHD, SW & Neonatal & $+/-$ & 20.5 & 20.5 & 5 & 36.15 & 4.68 & 3.67 & 487.5 & $N / A$ \\
\hline 4 & 21-OHD, SW & Neonatal & $+/+$ & 24.1 & 24.1 & 5 & 128.7 & 26.1 & 15.28 & 51.5 & $\mathrm{~N} / \mathrm{A}$ \\
\hline 5 & 21-OHD, SW & Neonatal & $+/+$ & 20.7 & 20.7 & 5 & 271.5 & 83.8 & 6.71 & 702 & $\mathrm{~N} / \mathrm{A}$ \\
\hline 6 & 21-OHD, SW & 0.8 & $+/+$ & 19.8 & 19.8 & 5 & 7.34 & 3.50 & $>37$ & 350.9 & $\mathrm{~N} / \mathrm{A}$ \\
\hline 7 & 21-OHD, SW & Neonatal & $+/+$ & 15.9 & 15.9 & 5 & 8.86 & 8.85 & 32.01 & 317.1 & N/A \\
\hline 8 & 21-OHD, SW & Neonatal & $+/+$ & 15.5 & 15.5 & 5 & 2.47 & 0.37 & 0.20 & 205.3 & $\mathrm{~N} / \mathrm{A}$ \\
\hline \multicolumn{12}{|c|}{ Patients without TARTs } \\
\hline 9 & 21-OHD, SV & 3.5 & $-/-$ & 29.4 & - & 5 & 66.74 & 17.72 & 12.52 & 273.8 & $\mathrm{~N} / \mathrm{A}$ \\
\hline 10 & 21-OHD, SV & 6.5 & $-/-$ & 17.0 & - & 5 & 15.18 & 8.38 & 14.07 & 505.4 & $\mathrm{~N} / \mathrm{A}$ \\
\hline 11 & 21-OHD, SV & 8.8 & $-/-$ & 18.2 & - & 5 & 2.12 & 6.94 & 31.39 & 148 & $\mathrm{~N} / \mathrm{A}$ \\
\hline 12 & 21-OHD, SW & Neonatal & $-/-$ & 20.5 & - & 5 & 522.2 & 12.42 & 0.76 & 162.6 & N/A \\
\hline 13 & 21-OHD, SW & 0.2 & $-/-$ & 20.7 & - & 5 & 9.84 & 1.97 & 22.13 & 623.4 & $\begin{array}{l}\text { Intron } 2 \text { splice mutation/ } \\
\text { Intron } 2 \text { splice mutation }\end{array}$ \\
\hline
\end{tabular}

$\mathrm{CAH}$, congenital adrenal hyperplasia; TART, testicular adrenal rest tumor; US, ultrasonography; ACTH, adrenocorticotrophic hormone; 17$\mathrm{OHP}$, 17-hydroxyprogesterone; 21-OHD, 21-hydroxlyase deficiency; SV, simple virilizing; SW, salt wasting; N/A, not applicable.

Table 2. A comparison of the clinical and biochemical parameters of CAH patients with and without TARTs

\begin{tabular}{lccc}
\hline Variable & TARTs patients $(\mathrm{n}=8)$ & Non-TARTs patients $(\mathrm{n}=5)$ & P-value \\
\hline Age at scrotal US $(\mathrm{yr})$ & $20.2(15.5-24.1)$ & $20.5(17.0-29.4)$ & 0.769 \\
Height $(\mathrm{cm})$ & $164.0(146.0-179.0)$ & $164.6(157.5-169.0)$ & 0.608 \\
Weight $(\mathrm{kg})$ & $62.0(46.0-117.0)$ & $70.8(52.0-82.0)$ & 0.942 \\
BSA $\left(\mathrm{m}^{2}\right)$ & $1.68(1.37-2.33)$ & $1.78(1.54-1.96)$ & 0.826 \\
Hydrocortisone equivalent dose $\left(\mathrm{mg} / \mathrm{m}^{2}\right)^{\mathrm{a})}$ & $21.1(14.6-24.7)$ & $22.2(19.5-33.7)$ & 0.272 \\
ACTH $(\mathrm{pg} / \mathrm{mL})^{\mathrm{a}}$ & $144.6(39.0-514.8)$ & $36.5(6.4-111.5)$ & 0.040 \\
$17-O H P(\mathrm{ng} / \mathrm{mL})^{\mathrm{a})}$ & $12.3(7.6-105.2)$ & $6.9(1.6-13.8)$ & 0.079 \\
Testosterone $(\mathrm{ng} / \mathrm{dL})^{\mathrm{a})}$ & $260.1(181.1-611.6)$ & $254.0(157.0-589.0)$ & 0.884 \\
\hline Vas a & & & \\
\hline
\end{tabular}

Values are presented as median (range).

$P$-values were determined using the Mann-Whitney U-test for continuous variables.

$\mathrm{CAH}$, congenital adrenal hyperplasia; TART, testicular adrenal rest tumor; US, ultrasonography; BSA, body surface area; ACTH, adrenocorticotrophic hormone; 17-OHP, 17-hydroxyprogesterone.

a) The hydrocortisone dose as well as the serum $\mathrm{ACTH}, 17-\mathrm{OHP}$, and testosterone levels represent the mean of the values in the immediate 5 years prior to the first scrotal US. 
conducting the first scrotal US were also estimated. There were no clear differences in other laboratory values except for the mean serum ACTH level, which was higher in the TART group than the non-TARTs group $(P<0.05)$. The median value was $144.6 \mathrm{pg} / \mathrm{mL}$ (range, $39.0-514.8 \mathrm{pg} / \mathrm{mL}$ ) in patients with TARTs, and $36.5 \mathrm{pg} / \mathrm{mL}$ (range, $6.4-111.5 \mathrm{pg} / \mathrm{mL}$ ) in patients without TARTs.

The transverse and longitudinal diameters of the TART measured by the scrotal US and the follow-up results are compared in Table 3 . TARTs were bilateral in 6 out of the 8 patients $(75 \%)$. All patients with TARTs were in stage 2, which indicates hypertrophy and hyperplasia of the adrenal rest cells without compression of the rete testis. The patients were all treated with hydrocortisone (median, $21.1 \mathrm{mg} / \mathrm{m}^{2}$ per day). In patients with SW type, fludrocortisone $(0.1 \mathrm{mg} /$ day $)$ was added to the treatment regimen. In 4 out of the 8 patients (cases 3, 6, 7 and 8 ), we maintained the treatment of hydrocortisone for the same dose before and after the diagnosis of TARTs. In contrast, the hydrocortisone doses of the 4 other patients (cases 1, 2, 4, and 5) were increased after detection of the tumor, which was based on the therapeutic control of the hormonal status. Among the 8 patients with TARTs, 5 patients had follow-up scrotal US, and the follow-up duration was from 6 months to 1 year. The tumor size decreased in 3 cases (cases 5, 6, and 8), slightly increased in 1 case (case 7), and had no interval changes in another case (case 3). Among the 3 patients whose tumor size decreased, 1 patient received a higher dose of hydrocortisone for therapeutic control $\left(19.5 \mathrm{mg} / \mathrm{m}^{2}\right.$ before diagnosis, and 26.0 $\mathrm{mg} / \mathrm{m}^{2}$ after diagnosis) while the other 2 patients maintained the same dose of the medication. There seems to be no significant association between the dose adjustment of the hydrocortisone and the changes in tumor size. Regardless of the treatment dose adjustment, the patients with decreased tumor size all demonstrated significantly decreased ACTH levels compared to the baseline study $(317.0-29.1 \mathrm{pg} / \mathrm{mL}$ in case $5 ; 89.4-6.5 \mathrm{pg} / \mathrm{mL}$ in case 6 ; and $42.6-6.0 \mathrm{pg} / \mathrm{mL}$ in case 8 ). In contrast, 1 patient (case 7 ) with increased tumor size did not show a significant decrease in the serum ACTH level (39.0-30.8 pg/mL).

Surgical biopsy was performed in 1 case (case 2). This patient was diagnosed with the SV type of CAH at 15.6 years old. Abdominopelvic computed tomography scan was performed because of a car accident, and he was incidentally diagnosed with adrenal cortical carcinoma. He underwent resection surgery of the left adrenal gland when he was 16 years old, and was treated with hydrocortisone $14.59 \mathrm{mg} / \mathrm{m}^{2}$ daily. Five years later, he had scrotal US for TARTs screening, and was diagnosed as TART. Because the US result could not rule out the possibility of tumor metastasis, biopsy of the scrotal mass was performed in this case. The results of the pathologic exam were consistent with TARTs and inhibin-alpha was positive in the tumor cells on immunohistochemical staining, suggesting the cells were of adrenal cortical origin.

\section{Discussion}

The prevalence of TARTs in males with CAH was $61.5 \%$ in this study. Several previous studies showed variable prevalence $(0 \%-94 \%)^{6,9-11)}$ in various study populations, including childhood, adolescence and adulthood. Higher prevalence was found in studies involving adult patients, whereas a lower prevalence was reported in the studies involving younger patients ${ }^{5,25)}$. Compared to the previous studies, the relatively higher TART prevalence in this study may be due to the advanced pubertal stage in the patients who had scrotal US. The patients

Table 3. A comparison of tumor sizes and stages, mean serum ACTH levels, and steroid treatment doses among CAH patients with TARTs, at the time of diagnosis and in the follow-up period ( 6 months or 1 year)

\begin{tabular}{|c|c|c|c|c|c|c|c|c|c|c|c|c|}
\hline \multirow[b]{2}{*}{ Case } & \multicolumn{5}{|c|}{ At diagnosis } & \multicolumn{5}{|c|}{ Follow-up } & \multirow[b]{2}{*}{$\begin{array}{c}\text { Mass } \\
\text { size change }\end{array}$} & \multirow[b]{2}{*}{$\begin{array}{l}F / U \\
\text { perioc } \\
(\mathrm{mo})\end{array}$} \\
\hline & $\begin{array}{c}\text { Diameter at } \\
\text { diagnosis } \\
(\mathrm{mm})\end{array}$ & $\begin{array}{l}\text { Tumor } \\
\text { stage }\end{array}$ & $\begin{array}{l}\text { Mean } \\
\text { ACTH } \\
\text { level }^{\text {a) }}\end{array}$ & $\begin{array}{l}\text { Hydrocortisone } \\
\text { dose }\left(\mathrm{mg} / \mathrm{m}^{2}\right)\end{array}$ & $\begin{array}{l}\text { Fludrocortisone } \\
\text { dose (mg/day) }\end{array}$ & $\begin{array}{l}\text { Diameter } \\
\quad \text { at } \\
\text { follow-up } \\
\text { (mm) }\end{array}$ & $\begin{array}{l}\text { Tumor } \\
\text { stage }\end{array}$ & $\begin{array}{l}\text { Mean } \\
\text { ACTH } \\
\text { Level }^{\text {b) }}\end{array}$ & $\begin{array}{l}\text { Hydrocortisone } \\
\text { dose }\left(\mathrm{mg} / \mathrm{m}^{2}\right)\end{array}$ & $\begin{array}{l}\text { Fludrocortisone } \\
\text { dose (mg/day) }\end{array}$ & & \\
\hline 1 & $4 \times 5(L)$ & 2 & 185.5 & 24.7 & - & - & 2 & 92.2 & 30.9 & - & - & - \\
\hline 2 & $\begin{array}{l}27 \times 27(\mathrm{R}) / \\
23 \times 31(\mathrm{~L})\end{array}$ & 2 & 514.8 & 14.6 & - & - & 2 & 176.5 & 29.2 & - & - & - \\
\hline 3 & $4 \times 8(R)$ & 2 & 103.7 & 24.4 & 0.1 & $4 \times 8(R)$ & 2 & 22.2 & Same & 0.1 & No change & 12 \\
\hline 4 & $\begin{array}{l}11 \times 15(\mathrm{R}) / \\
18 \times 20(\mathrm{~L})\end{array}$ & 2 & 340.5 & 17.2 & 0.1 & - & 2 & 212.0 & 21.5 & 0.1 & - & - \\
\hline 5 & $\begin{array}{l}25 \times 15(\mathrm{R}) / \\
23 \times 10(\mathrm{~L})\end{array}$ & 2 & 317.0 & 19.5 & 0.1 & $\begin{array}{c}15 \times 10(\mathrm{R}) / \\
15 \times 8(\mathrm{~L})\end{array}$ & 2 & 29.1 & 26 & 0.1 & Decreased & 12 \\
\hline 6 & $\begin{array}{c}38 \times 16(\mathrm{R}) / \\
28 \times 20(\mathrm{~L})\end{array}$ & 2 & 89.4 & 18.4 & 0.1 & $\begin{array}{l}20 \times 13(\mathrm{R}) / \\
22 \times 16(\mathrm{~L})\end{array}$ & 2 & 6.5 & Same & 0.1 & Decreased & 12 \\
\hline 7 & $\begin{array}{c}10 \times 15(\mathrm{R}) / \\
10 \times 18(\mathrm{~L})\end{array}$ & 2 & 39.0 & 23.3 & 0.1 & $\begin{array}{l}15 \times 15(\mathrm{R}) / \\
10 \times 20(\mathrm{~L})\end{array}$ & 2 & 30.8 & Same & 0.1 & $\begin{array}{l}\text { Slightly } \\
\text { increased }\end{array}$ & 6 \\
\hline 8 & $\begin{array}{l}25 \times 30(\mathrm{R}) / \\
23 \times 33(\mathrm{~L})\end{array}$ & 2 & 42.6 & 22.7 & 0.1 & $\begin{array}{c}25 \times 30(\mathrm{R}) / \\
15 \times 23(\mathrm{~L})\end{array}$ & 2 & 6.0 & Same & 0.1 & Decreased & 10 \\
\hline
\end{tabular}

$\mathrm{ACTH}$, adrenocorticotrophic hormone; $\mathrm{CAH}$, congenital adrenal hyperplasia; TART, testicular adrenal rest tumor.

a)The average value of serum ACTH levels for 5 years before diagnosis of TART. ') The average value of serum ACTH levels for 6 months to 1 year during the follow-up period. 
involved in our study were all in the Tanner 5 pubertal stage. The youngest patient with TART was 15.5 years old and was diagnosed with TART at his first US screening. Thus, we gave attention about the existence of tumor before conducting the scrotal US. The youngest CAH patient with TART reported in the literature was only several weeks old ${ }^{26)}$. Therefore, to find a more precise prevalence, earlier detection of tumor with US screening in male CAH patients, and longitudinal study for a longer period of time is needed.

It has been proven that TARTs consist of cells with clear features of adrenocortical tissue ${ }^{27-29)}$. However, the etiology and growth promoting factors of TARTs are still unclear, making it difficult to define the steps necessary for preventing tumor growth ${ }^{25}$. In the majority of the reported studies, patients with TARTs had poor metabolic control ${ }^{30,31)}$, and uncontrolled hormonal status, which is believed to be one of the important causes in the pathogenesis of TARTs. Among the hormones, ACTH is the most frequently suggested causative and growth promoting factor in TARTs ${ }^{27,32)}$. However, there is some controversy regarding this hypothesis, since TARTs are also diagnosed in adequately treated children and may not develop in adult male CAH patients with poorly controlled disease ${ }^{27}$. In our study, the median value of the 5-year mean ACTH level in the TARTs group was significantly higher than in the nonTARTs group. In addition, according to the follow-up results, the 3 patients whose tumor size decreased showed markedly lower serum ACTH levels. Therefore, we can support the previous hypothesis that exposure to high concentrations of the serum ACTH level can be a major factor in the development of TARTs. This hypothesis could be taken into consideration for the treatment of TARTs. In addition, monitoring and education for good adherence to medication are very important, especially in adolescent and adult patients. In our study, even though more than usual dosages of hydrocortisone were prescribed, mean ACTH levels were higher than the normal range, suggesting poor adherence.

There are several studies concerning other contributing factors of TART, and some results reported luteinizing hormone could be a contributing factor ${ }^{33)}$. Recently, studies have shown that the tumor growth in patients with CAH may not only be stimulated by ACTH, but also by elevated angiotensin II level ${ }^{15)}$. However, in this study, the reviewed hormonal parameters (17OHP, testosterone) except for ACTH and the mean levels of hydrocortisone doses between the two patient groups did not show any significant differences. To find other contributing factors of TARTs, further investigations must be explored in larger populations.

The treatment of TARTs has not been well defined thus far. Several studies suggested that intensifying hydrocortisone therapy might lead to a reduction in tumor size by suppression of ACTH secretion ${ }^{18)}$. However, adequate ACTH suppression with high-dose hydrocortisone treatment was not always successful in reducing the tumor size ${ }^{6,19,34)}$. In our followup results, there were no significant differences in tumor size associated with the hydrocortisone dose. Nevertheless, the serum ACTH level demonstrated remarkable decline in patients with decreased tumor size. Although some case reports ${ }^{35,36}$ have reported a reduction in the size of TARTs after a higher dose of hydrocortisone treatment, which recurred after decreasing the dose, we cannot make a conclusion from this limited observation. In order to clarify the treatment methods for TARTs, studies involving larger patient populations who will be followed for longer time periods, will need to be explored.

Since TARTs do not have malignant features, there is no need to treat or remove the tumors at an early stage. Surgical removal of the tumor is recommended when the tumor has advanced beyond stage $3^{32,37)}$. However, because of the localization to the rete testis regardless of the size, TARTs may compress the seminiferous tubules leading to obstruction and irreversible damage ${ }^{25,34,37}$. Therefore, early detection and proper management of TARTs are important before the onset of permanent damage ${ }^{11)}$. Previous studies recommend semen analysis and spermatograms with subsequent cryopreservation, if needed, in order to improve fertility in patients with TARTs $^{26,30)}$. In our study, patients with TARTs were all in tumor stage 2 and did not undergo semen analysis due to their early tumor stage. Since the analysis was not performed, the impact of TARTs on infertility cannot be established in this study. However, considering the long term preservation of fertility in TARTs patients, we are planning to have semen analysis from early stage of the tumor.

As a screening tool, scrotal US offers many advantages including low cost, technical simplicity, and non-invasiveness ${ }^{24)}$. The minimum testicular tumor size that was detected by scrotal US is approximately $2 \mathrm{~mm}$ in diameter ${ }^{24}$. In our study, none of the tumors were detected by physical examination and none of the patients with TARTs complained of symptoms of gonadal dysfunction at the time of diagnosis. As a scrotal US offers efficient screening modality and TARTs are usually asymptomatic, it is important for the TART patients to have scrotal US before presenting any gonadal symptoms. Claahsen-van der Grinten et al. ${ }^{12)}$ proposed that screening for TARTs in male CAH patient should start at 8 years old. Other studies $^{22,38,39)}$ have suggested initiating scrotal US screening during the pubertal period. Therefore, scrotal US screening must be performed at least before puberty and regularly during adulthood in male CAH patients in order to prevent infertility. Also, regular screening by scrotal US should be performed at least every 2 years in early childhood and annually in the peripubertal period ${ }^{18)}$.

In conclusion, the prevalence of TARTs was $61.5 \%$ in our group of male patients with $\mathrm{CAH}$. Based on our results, the serum ACTH level might be associated with the growth promoting factor for TARTs; however, the exact mechanism of progression and regression has not been clearly identified. Although no significant differences in tumor size were identified according to hydrocortisone dose, studies involving larger patient populations who are followed for longer periods of time are necessary in order to clarify the treatment of TARTs. Since all the patients with TARTs in our study did not have palpable 
and clinically detectable tumors, it is very important for scrotal US screening to be initiated before puberty. Scrotal US should be followed up every 1-2 years because of the possibility of increases in tumor size and the risk of infertility.

\section{Conflict of interest}

No potential conflict of interest relevant to this article was reported.

\section{References}

1. Speiser PW, Azziz R, Baskin LS, Ghizzoni L, Hensle TW, Merke DP, et al. Congenital adrenal hyperplasia due to steroid 21-hydroxylase deficiency: an Endocrine Society clinical practice guideline. J Clin Endocrinol Metab 2010;95:4133-60.

2. Valentino R, Savastano S, Tommaselli AP, Scarpitta MT, Dorato M, Gigante M, et al. Success of glucocorticoid replacement therapy on fertility in two adult males with 21-CAH homozygote classic form. J Endocrinol Invest 1997;20:690-4.

3. Sahakitrungruang T. Clinical and molecular review of atypical congenital adrenal hyperplasia. Ann Pediatr Endocrinol Metab 2015;20:1-7.

4. Claahsen-van der Grinten HL, Stikkelbroeck NM, Sweep CG, Hermus AR, Otten BJ. Fertility in patients with congenital adrenal hyperplasia. J Pediatr Endocrinol Metab 2006;19:677-85.

5. Reisch N, Flade L, Scherr M, Rottenkolber M, Pedrosa Gil F, Bidlingmaier M, et al. High prevalence of reduced fecundity in men with congenital adrenal hyperplasia. J Clin Endocrinol Metab 2009;94:1665-70.

6. Stikkelbroeck NM, Otten BJ, Pasic A, Jager GJ, Sweep CG, Noordam K, et al. High prevalence of testicular adrenal rest tumors, impaired spermatogenesis, and Leydig cell failure in adolescent and adult males with congenital adrenal hyperplasia. J Clin Endocrinol Metab 2001;86:5721-8.

7. Larson CP, Reberger CC. Macrogenitosomia precox with adrenal hyperplasia and bilateral heterotopic adrenal cortical tissue of the testes. West J Surg Obstet Gynecol 1954;62:602-6.

8. Jin HY, Choi JH, Kim GH, Lee CS, Yoo HW. Testicular adrenal rest tumors in a patient with untreated congenital adrenal hyperplasia. Korean J Pediatr 2011;54:137-40.

9. Avila NA, Premkumar A, Merke DP. Testicular adrenal rest tissue in congenital adrenal hyperplasia: comparison of MR imaging and sonographic findings. AJR Am J Roentgenol 1999;172:1003-6.

10. Willi U, Atares M, Prader A, Zachmann M. Testicular adrenal-like tissue (TALT) in congenital adrenal hyperplasia: detection by ultrasonography. Pediatr Radiol 1991;21:284-7.

11. Cabrera MS, Vogiatzi MG, New MI. Long term outcome in adult males with classic congenital adrenal hyperplasia. J Clin Endocrinol Metab 2001;86:3070-8.

12. Claahsen-van der Grinten HL, Hermus AR, Otten BJ. Testicular adrenal rest tumours in congenital adrenal hyperplasia. Int J Pediatr Endocrinol 2009;2009:624823.

13. Barwick TD, Malhotra A, Webb JA, Savage MO, Reznek RH. Embryology of the adrenal glands and its relevance to diagnostic imaging. Clin Radiol 2005;60:953-9.

14. Murphy H, George C, de Kretser D, Judd S. Successful treatment with ICSI of infertility caused by azoospermia associated with adrenal rests in the testes: case report. Hum Reprod 2001;16:263-7.

15. Claahsen-van der Grinten HL, Otten BJ, Sweep FC, Span PN, Ross HA, Meuleman EJ, et al. Testicular tumors in patients with congenital adrenal hyperplasia due to 21-hydroxylase deficiency show functional features of adrenocortical tissue. J Clin Endocrinol Metab 2007;92:3674-80.

16. Avila NA, Premkumar A, Shawker TH, Jones JV, Laue L, Cutler GB Jr. Testicular adrenal rest tissue in congenital adrenal hyperplasia: findings at Gray-scale and color Doppler US. Radiology 1996;198:99-104.

17. Martinez-Aguayo A, Rocha A, Rojas N, García C, Parra $\mathrm{R}$, Lagos M, et al. Testicular adrenal rest tumors and Leydig and Sertoli cell function in boys with classical congenital adrenal hyperplasia. J Clin Endocrinol Metab 2007;92:4583-9.

18. Aycan Z, Bas VN, Cetinkaya S, Yilmaz Agladioglu S, Tiryaki T. Prevalence and long-term follow-up outcomes of testicular adrenal rest tumours in children and adolescent males with congenital adrenal hyperplasia. Clin Endocrinol (Oxf) 2013;78:667-72.

19. Cakir ED, Mutlu FS, Eren E, Pasa AO, Saglam H, Tarim O. Testicular adrenal rest tumors in patients with congenital adrenal hyperplasia. J Clin Res Pediatr Endocrinol 2012;4:94-100.

20. Tanner JM, Whitehouse RH. Clinical longitudinal standards for height, weight, height velocity, weight velocity, and stages of puberty. Arch Dis Child 1976;51:170-9.

21. Speiser PW, White PC. Congenital adrenal hyperplasia. N Engl J Med 2003;349:776-88.

22. Stikkelbroeck NM, Suliman HM, Otten BJ, Hermus AR, Blickman JG, Jager GJ. Testicular adrenal rest tumours in postpubertal males with congenital adrenal hyperplasia: sonographic and MR features. Eur Radiol 2003;13:1597603.

23. Vanzulli A, DelMaschio A, Paesano P, Braggion F, Livieri C, Angeli E, et al. Testicular masses in association with adrenogenital syndrome: US findings. Radiology 1992;183:425-9.

24. Avila NA, Shawker TS, Jones JV, Cutler GB Jr, Merke DP. Testicular adrenal rest tissue in congenital adrenal hyperplasia: serial sonographic and clinical findings. AJR Am J Roentgenol 1999;172:1235-8.

25. Claahsen-van der Grinten HL, Sweep FC, Blickman JG, 
Hermus AR, Otten BJ. Prevalence of testicular adrenal rest tumours in male children with congenital adrenal hyperplasia due to 21-hydroxylase deficiency. Eur J Endocrinol 2007;157:339-44.

26. Pierre P, Despert F, Tranquart F, Coutant R, Tardy V, Kerlan V, et al. Adrenal rest tissue in gonads of patients with classical congenital adrenal hyperplasia: multicenter study of 45 French male patients. Ann Endocrinol (Paris) 2012;73:51522.

27. Claahsen-van der Grinten HL, Dehzad F, Kamphuis-van Ulzen K, de Korte CL. Increased prevalence of testicular adrenal rest tumours during adolescence in congenital adrenal hyperplasia. Horm Res Paediatr 2014;82:238-44.

28. Val P, Jeays-Ward K, Swain A. Identification of a novel population of adrenal-like cells in the mammalian testis. Dev Biol 2006;299:250-6.

29. Clark RV, Albertson BD, Munabi A, Cassorla F, Aguilera G, Warren DW, et al. Steroidogenic enzyme activities, morphology, and receptor studies of a testicular adrenal rest in a patient with congenital adrenal hyperplasia. J Clin Endocrinol Metab 1990;70:1408-13.

30. Stikkelbroeck NM, Hermus AR, Suliman HM, Jager GJ, Otten BJ. Asymptomatic testicular adrenal rest tumours in adolescent and adult males with congenital adrenal hyperplasia: basal and follow-up investigation after 2.6 years. J Pediatr Endocrinol Metab 2004;17:645-53.

31. Claahsen-van der Grinten HL, Otten BJ, Sweep FC, Hermus AR. Repeated successful induction of fertility after replacing hydrocortisone with dexamethasone in a patient with congenital adrenal hyperplasia and testicular adrenal rest tumors. Fertil Steril 2007;88:705.e5-8.
32. Bonaccorsi AC, Adler I, Figueiredo JG. Male infertility due to congenital adrenal hyperplasia: testicular biopsy findings, hormonal evaluation, and therapeutic results in three patients. Fertil Steril 1987;47:664-70.

33. Benvenga S, Smedile G, Lo Giudice F, Trimarchi F. Testicular adrenal rests: evidence for luteinizing hormone receptors and for distinct types of testicular nodules differing for their autonomization. Eur J Endocrinol 1999;141:231-7.

34. Poyrazoglu S, Saka N, Agayev A, Yekeler E. Prevalence of testicular microlithiasis in males with congenital adrenal hyperplasia and its association with testicular adrenal rest tumors. Horm Res Paediatr 2010;73:443-8.

35. Sha YW, Song YQ, Zheng LK, Ma XM, Yang D, Huang P, et al. Congenital adrenal hyperplasia complicated by testicular adrenal rest tumors: one-case clinical analysis. Zhonghua Nan Ke Xue 2010;16:816-21.

36. Mouritsen A, Juul A, Jørgensen N. Improvement of semen quality in an infertile man with 21-hydroxylase deficiency, suppressed serum gonadotropins and testicular adrenal rest tumours. Int J Androl 2010;33:518-20.

37. Claahsen-van der Grinten HL, Otten BJ, Takahashi S, Meuleman EJ, Hulsbergen-van de Kaa C, Sweep FC, et al. Testicular adrenal rest tumors in adult males with congenital adrenal hyperplasia: evaluation of pituitarygonadal function before and after successful testissparing surgery in eight patients. J Clin Endocrinol Metab 2007;92:612-5.

38. White PC, Speiser PW. Congenital adrenal hyperplasia due to 21-hydroxylase deficiency. Endocr Rev 2000;21:245-91.

39. Hughes IA. Congenital adrenal hyperplasia: a lifelong disorder. Horm Res 2007;68 Suppl 5:84-9. 